Scientific Review - Engineering and Environmental Sciences (2021), 30 (2), 315-326

Sci. Rev. Eng. Env. Sci. (2021), 30 (2)

Przegląd Naukowy - Inżynieria i Kształtowanie Środowiska (2021), 30 (2), 315-326

Prz. Nauk. Inż. Kszt. Środ. (2021), 30 (2)

http://iks.pn.sggw.pl

DOI 10.22630/PNIKS.2021.30.2.27

Mohammed KADHUM ${ }^{1}$, Zainab MAHDI ${ }^{2}$, Yousif FUNFAKH ${ }^{1}$, Zaid MOHAMMED ${ }^{3}$, Mustafa ABDULRAHEEM ${ }^{1,4}$, Michaela GKANTOU ${ }^{5}$

${ }^{1}$ University of Babylon, College of Engineering

${ }^{2}$ Middle Technical University - Baghdad, Technical Engineering College

${ }^{3}$ University of Technology - Baghdad, Engineering College

${ }^{4}$ Department of planning and development, General Company of electricity distribution for the middle region, Karbala branch

${ }^{5}$ Liverpool John Moores University, School of Civil Engineering and Built Environment

\title{
Experimental investigation on the post-fire performance of reactive powder concrete columns
}

Key words: post-fire, concrete, behavior, third term, fourth date, fifth date, max sixth

\section{Introduction}

Reactive powder concrete (RPC) is gaining increasing attention, from both academia and the construction industry, because of its favourable characteristics, such as good dynamic mechanical properties (Tuama, Kadhum, Alwash, Al-Khafaji \& Abdulraheem, 2020). Therefore, RPC, since it was developed during the 1990s, has been widely applied in different construction industry fields, such as bridges, roads, military shelters, and municipal works (Yan, 2009; Kadhum, Alwash, Tuama \& Abdulraheem, 2020). Numerous studies
(Liu \& Huang, 2009; Tai, Pan \& Kung, 2011) have been performed to investigate the performance of concrete members exposed to fire in two phases; the first, investigate the impact of fire on the main mechanical characteristics as a construction material, and the second, focuses on the analysis of the structural behavior during the fire. Suddenly exposure of RPC to elevated temperatures might cause a spalling incident; this is probably due to the internal gas pore pressure increments while heating (Hager, Zdeb \& Krzemien, 2013). "Spalling that caused by the rapid concrete loss after the fire temperatures reach to the inner concrete's layers core, thus increment in the transmission rate of concrete heat to the deeper member's layers" (Abdulraheem \& Kadhum, 2018). The 
temperature range of fire could be subdivided into two strength loss terms in RPC: $23-200^{\circ} \mathrm{C}$ and $300-500^{\circ} \mathrm{C}$. Within the range $23-200^{\circ} \mathrm{C}, \mathrm{RPC}$ maintains or maybe gains an increase in the original strength. In the range $300-500^{\circ} \mathrm{C}$, RPC loses abundant amounts of genuine strength (Kadhum, 2015). Based on their position in the structure, columns may be exposed to fire on one side, two sides, three sides, or all four sides, which is an extremely critical situation. It can be seen so far that experimental studies relating to this new ultra high strength fiber reinforced concrete are still limited. According to that, the information available on the fire performance of RPC columns need to be conducted further. The purpose of the present study is to an extremely critical situation (Kodur \& Raut, 2012), quantify some of the parameters influencing the residual strength and surface spalling of RPC columns to provide recommendations for fire-safe constructions. Experiments on RPC columns were performed through the manufacturing of a special smart system to represent the real condition of fire. The following parameters are considered: reinforcement ratio, temperature levels, and duration of exposure to fire. This research aims to compare the structural behavior of the concentrically loaded RPC and NSC column specimens after exposure to fire at various temperature levels.

\section{Experimental program}

The experimental work consists of two stages. The first stage includes the materials utilized, preparation, casting, and curing of the test samples. The second stage comprises (i) loading up to $25 \%$ of the ultimate load before heating, and (ii) heating with keeping the $25 \%$ loading constant (iii) loading after the heating process is finished and until failure, whereas the results for columns that are not heated are measured after the applied load only.

\section{Depiction of the tested column specimens}

The tested columns have dimensions of $900 \mathrm{~mm}$ long and a square cross-section of $100 \times 100 \mathrm{~mm}$, as demonstrated in Figure 1. The experimental program consists of 21 reduced-scale columns, which were cast, and tested up to failure under concentric compression loading. These columns were categorized into three groups according to their variables: the first group consisted of seven columns of RPC reinforced with $4 \varnothing 6 \mathrm{~mm}$ as longitudinal reinforcement and $\varnothing 5 \mathrm{~mm}$ bars were utilized for ties (lateral reinforcement), the second group consisted of seven columns of RPC that were without reinforcement to investigate the impact of column reinforcement after the fire at different heating levels, and the third group consisted of seven columns of NSC reinforced with $4 \varnothing 6 \mathrm{~mm}$ as longitudinal reinforcement and $\varnothing 5 \mathrm{~mm}$ bars were utilized for ties.

\section{Constituent materials and fabrication}

Two kinds of concrete were investigated in this investigation: the RPC for the specimens of the first and the second group and the NSC mix for the 


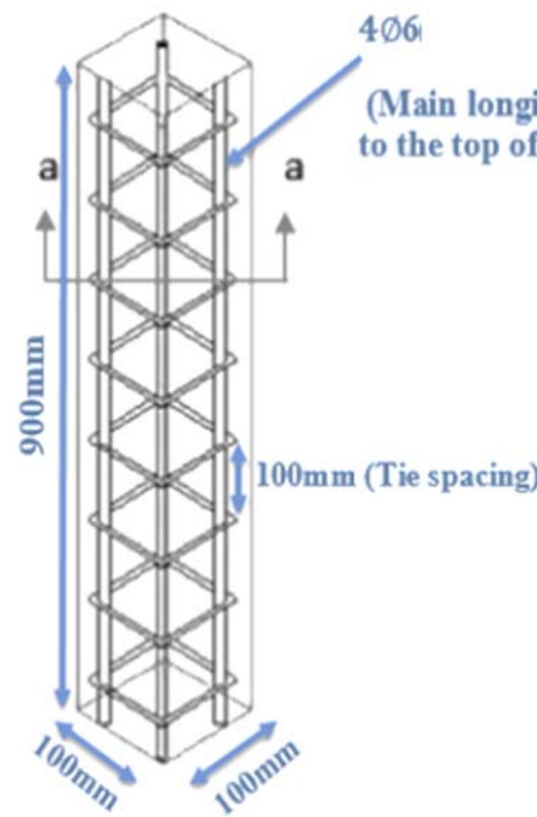

FIGURE 1. Characterization of the columns

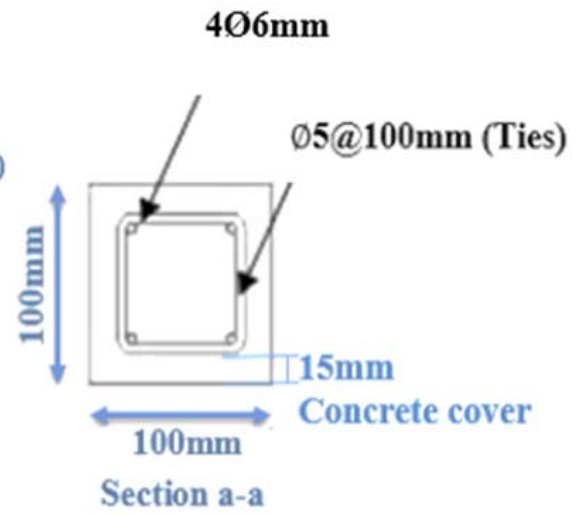

(SP) which is known commercially as Hyperplastic PC200. Sand amount of $1,050 \mathrm{~kg} \cdot \mathrm{m}^{-3}$ with a maximum particle size of $600 \mu \mathrm{m}$ and $230 \mathrm{~kg} \cdot \mathrm{m}^{-3}$ of brass-coated steel micro-fibers $(0.18 \mathrm{~mm}$ in diameter and $13 \mathrm{~mm}$ long) and tensile strength of $2,300 \mathrm{MPa}$ were used for all RPC mixes. The NSC mix consisted of $550 \mathrm{~kg} \cdot \mathrm{m}^{-3}$ of OPC, $730 \mathrm{~kg} \cdot \mathrm{m}^{-3}$ of natural sand, $810 \mathrm{~kg} \cdot \mathrm{m}^{-3}$ of rounded gravel with a maximum size of $10 \mathrm{~mm}$, whilst the $\mathrm{w} / \mathrm{c}$ was 0.45 . The physical properties of fine and coarse aggregate

TABLE 1. Chemical characteristics of silica fume and cement

\begin{tabular}{|l|c|c|c|c|c|c|c|}
\hline Material & $\begin{array}{c}\mathrm{CaO} \\
{[\%]}\end{array}$ & $\begin{array}{c}\mathrm{SiO}_{2} \\
{[\%]}\end{array}$ & $\begin{array}{c}\mathrm{Al}_{2} \mathrm{O}_{3} \\
{[\%]}\end{array}$ & $\begin{array}{c}\mathrm{Fe}_{2} \mathrm{O}_{3} \\
{[\%]}\end{array}$ & $\begin{array}{c}\mathrm{SO}_{3} \\
{[\%]}\end{array}$ & $\begin{array}{c}\mathrm{MgO} \\
{[\%]}\end{array}$ & $\begin{array}{c}\text { Fineness } \\
{\left[\mathrm{m}^{2} \cdot \mathrm{kg}^{-1}\right]}\end{array}$ \\
\hline OPC & 62.23 & 19.86 & 4.88 & 3.48 & 2.47 & 2.47 & 340 \\
\hline Silica fume & 0.41 & 94.84 & 0.55 & 0.05 & 0.11 & 0.21 & 19980 \\
\hline
\end{tabular}


TABLE 2. Physical characteristics of fine and coarse aggregate

\begin{tabular}{|l|l|}
\hline \multicolumn{1}{|c|}{ Fine aggregate } & \multicolumn{1}{c|}{ Coarse aggregate } \\
\hline Fineness modulus $=2.6$ & Fineness modulus $=7.87$ \\
\hline Sulphate content $=0.09 \%$ & Bulk density $=1405 \mathrm{~kg} \cdot \mathrm{m}^{-3}$ \\
\hline Fine material passing from sieve $(75 \mu \mathrm{m})=4.2 \%$ & Max. size used $=10 \mathrm{~mm}$ \\
\hline Specific gravity $=2.65$ & Specific gravity $=2.75$ \\
\hline Water absorption $=0.74 \%$ & Water absorption $=1.2 \%$ \\
\hline
\end{tabular}

were determined as per the Iraqi Standard Specification IQS 45/1984 (Central Organization for Standardization and Quality Control [CCSQC], 1984) and are listed in Table 2. The mixing process utilized a horizontal rotary mixer of $0.09 \mathrm{~m}^{3}$ capacity for the column samples. The mixing method was adopted by our previous research (Abdulraheem, 2018) and approved to give satisfying workability and good dispersion of the materials.

\section{Heating process and testing methodology}

The slab specimens were tested under increasing concentric load up to failure at the age of 60 days utilizing a frame of $200 \mathrm{t}$ capacity. For each of the three groups, one specimen was used as a reference, which was tested up to the failure, without any fire exposure, while the other six specimens were initially loaded to $25 \%$ of the ultimate load; subsequently, they were subjected to fire temperature under $25 \%$ constant loading, assuming three different temperatures $\left(300,400\right.$ and $\left.500^{\circ} \mathrm{C}\right)$ and two durations ( 30 and $60 \mathrm{~min}$ ) for fire exposure, and finally were tested until failure after the exposure to fire is finished. For the columns, which were subjected to fire under loading, the target heating temperature was reached utilizing a sliding arm to control the fire distance to the surface of the columns and by monitoring the fire intensity thru controlling the liquefied petroleum gas pressure in the burners by utilizing an electric gas regulator control. A gas regulator control is an electronic valve used to supply a very fast and straight gas flow. The target temperatures were 300,400 , and $500^{\circ} \mathrm{C}$ for the exposed columns, while the reference columns were not exposed to fire (at room temperature). The duration of the temperature loading was either 30 or $60 \mathrm{~min}$, which was enough to warm up the sample to a uniform temperature (Abdulraheem, 2018; Abdulraheem \& Kadhum, 2018). The structural behavior of the RPC columns exposed to fire results from loading each column to $25 \%$ of the ultimate load before heating, utilizing load control at a loading rate of $1 \mathrm{kN} \cdot \mathrm{s}^{-1}$, and then heating these columns with keeping the $25 \%$ loading constant after that is loading them until failure. For columns that have not been heated, the results come solely from the applied load (Fig. 2). The vertical and lateral deformations were measured using two dial gauges with an accuracy of $0.001 \mathrm{~mm}$ per deviation to measure the deformations for each load increment. 


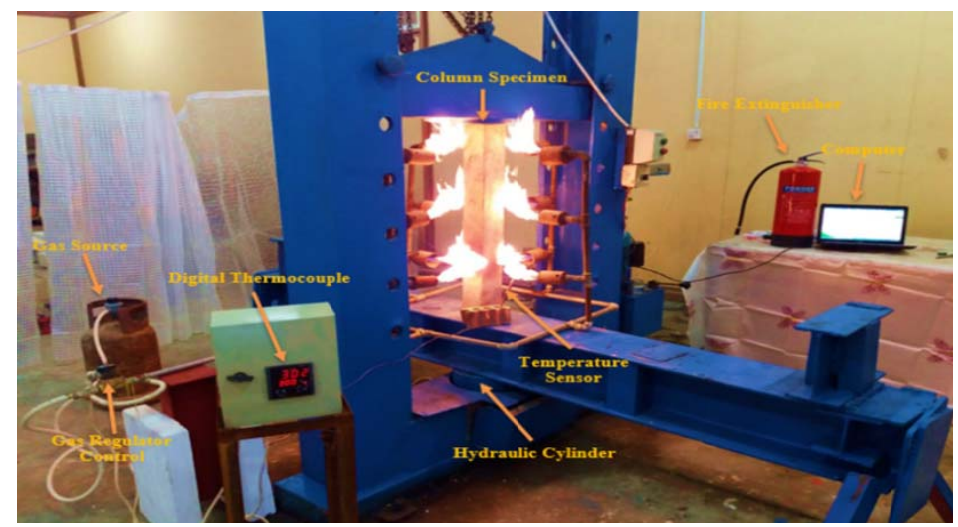

FIGURE 2. Experimental set-up

\section{Test results and discussion}

\section{Axial load and deformation}

The results in Table 3 showed that, after exposure to fire at $300^{\circ} \mathrm{C}$ for $30 \mathrm{~min}$, the ultimate strength of the RPC columns slightly increased, by $0.35 \%$ for the first group and $1.27 \%$ for the second group, which can be attributed to the further hydration of cementitious materials activated by elevated temperature (Abdulraheem, 2018; Abdulraheem \& Kadhum, 2018), while for NSC columns the bearing strength is decreased by $1.88 \%$. Exposure for $60 \mathrm{~min}$ shows a slight decrease in the ultimate strength of the RPC columns, by $0.58 \%$ for the first group and $0.954 \%$ for teh second, while the NSC continued to decrease by $3 \%$ of its ultimate load capacity. After 3-6 min, a crack propagation sound was heard, and small chunks from the surface layer fell out. The bearing strength started to decrease for the RPC columns after exposure to fire temperature of $400^{\circ} \mathrm{C}$ because thermal gradients developed in the concrete cross-section, and the moisture in the concrete was transformed to vapor and thus created pore pressure (Abdulraheem, 2018; Abdulraheem \& Kadhum, 2018). When pore pressure exceeded the tensile strength of the concrete, pieces of the concrete peeled off, and the ultimate loading capacity of the RPC columns decreased after $30 \mathrm{~min}$ of heating, by $28.52 \%$ for the first group and $35.29 \%$ for the second group, and after $60 \mathrm{~min}$ the ultimate load of the RPC decreased, by $31.92 \%$ for the first group and $37.28 \%$ for the second group. The ultimate load of the NSC column decreased by $5.64 \%$ and $11.9 \%$ after half an hour and an hour of exposure to fire, respectively. After 9-12 min of exposure to fire at $500^{\circ} \mathrm{C}$, the RPC specimens started to spall, big parts fell out, and the ultimate strength clearly decreased after $30 \mathrm{~min}$, by $48.78 \%$ for the first group and $71.55 \%$ for the second group, and after $60 \mathrm{~min}$, by $54.37 \%$ for the first group and $78.53 \%$ for the second group. These results demonstrate the effect of steel reinforcement, which contributes to saving the core of the column from the internal pressure that results from heating. The ultimate strength of 
TABLE 3. The results and details of the tested columns

\begin{tabular}{|c|c|c|c|c|}
\hline Group & $\begin{array}{c}\text { Column } \\
\text { designation }\end{array}$ & $\begin{array}{c}\text { Fire } \\
\text { duration } \\
{[\mathrm{min}]}\end{array}$ & $\begin{array}{c}\text { Ultimate } \\
\text { load capacity } \\
{[\mathrm{kN}]}\end{array}$ & Failure mode \\
\hline \multirow{7}{*}{1} & RPC-1-25 & - & 1070.5 & compression \\
\hline & RPC-1-300 & 30 & 1074 & compression \\
\hline & RPC-1-300 & 60 & 1064 & compression \\
\hline & RPC-1-400 & 30 & 765 & compression \\
\hline & RPC-1-400 & 60 & 728.5 & flexural \\
\hline & RPC-1-500 & 30 & 548 & compression \\
\hline & RPC-1-500 & 60 & 488.5 & flexural and compression \\
\hline \multirow{7}{*}{2} & RPC-0-25 & - & 872 & compression \\
\hline & RPC-0-300 & 30 & 883 & compression \\
\hline & RPC-0-300 & 60 & 864 & compression \\
\hline & RPC-0-400 & 30 & 564.5 & compression \\
\hline & RPC-0-400 & 60 & 547 & flexural \\
\hline & RPC-0-500 & 30 & 248 & flexural \\
\hline & RPC-0-500 & 60 & 187 & flexural and compression \\
\hline \multirow{7}{*}{3} & NSC-1-25 & - & 399 & compression \\
\hline & NSC-1-300 & 30 & 391.5 & compression \\
\hline & NSC-1-300 & 60 & 387 & compression \\
\hline & NSC-1-400 & 30 & 376.5 & compression \\
\hline & NSC-1-400 & 60 & 351.5 & compression \\
\hline & NSC-1-500 & 30 & 365 & compression \\
\hline & NSC-1-500 & 60 & 326.5 & compression \\
\hline
\end{tabular}

the NSC columns was reduced by $8.52 \%$ after $30 \mathrm{~min}$ and $18.2 \%$ after $60 \mathrm{~min}$.

The residual strength with the fire temperature level is shown in Figure 3. The results of the ultimate capacity of the columns with and without exposure to fire are given in Table 3 . It could be observed from Figure 3 that with increasing the fire duration from 30 to $60 \mathrm{~min}$, the decrement in the load-carrying capacity is not highly affected. However, when the column capacity is reached, the column fails either by crushing or flexural buckling.
The results proved that the resistance of NSC to fire is greater than that of RPC, which is severely spalled at elevated temperatures. The internal cracks are the main cause of spalling. There is, however, some doubt surrounding whether the surface layer is split partially or completely at various depths at the core of the column, taking into account that there is no considerable damage on the surface (Kadhum \& Mohammed, 2017). The vertical displacement of the reinforced RPC and NSC columns, as shown in Figure 4, has a similar trend 


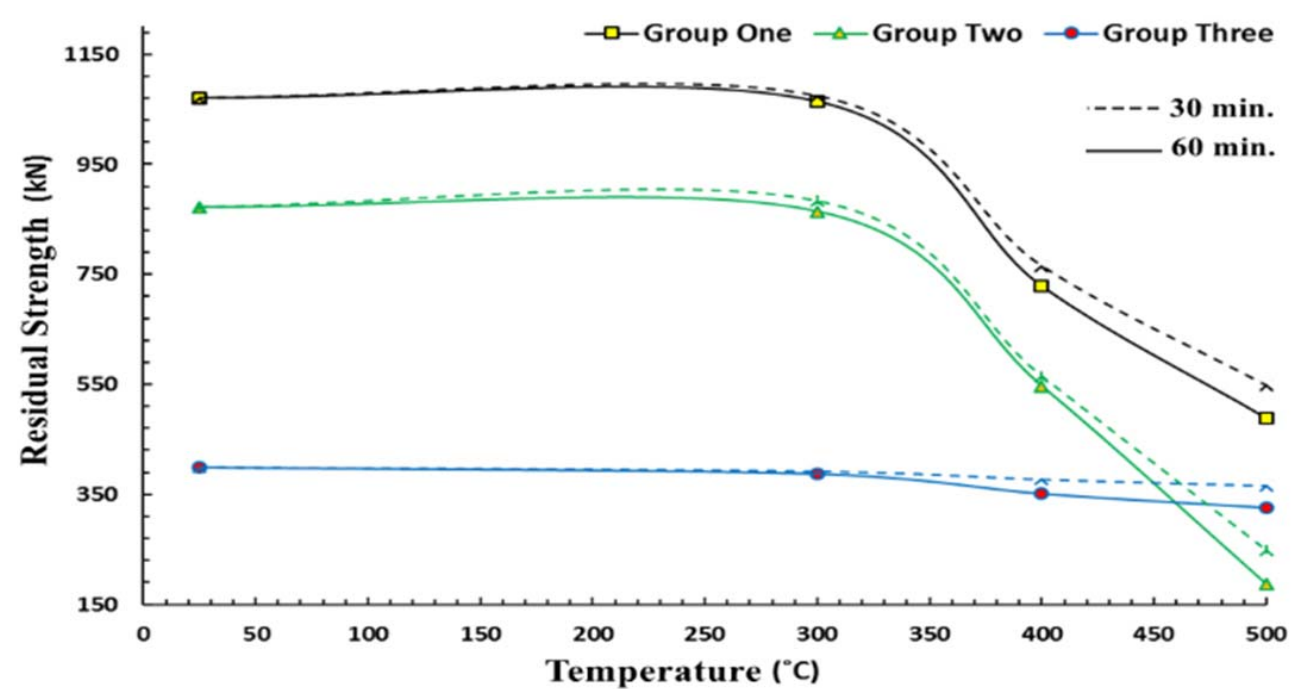

FIGURE 3. The residual strength with the change of temperature after half an hour and an hour of fire exposure

for all columns, but the maximum vertical displacement values of 4.21 and $2.54 \mathrm{~mm}$ for RPC and NSC columns, respectively, were reached after fire exposure at $400^{\circ} \mathrm{C}$ and for $60 \mathrm{~min}$. The vertical deformation during exposure to fire results from many reasons, such as thermal expansion, applied load, and creep. The positive and negative vertical deformation values indicate expansion and contraction, respectively, of the concentric column specimens. RPC and NSC column specimens exposed to fire at 300,400 , and $500^{\circ} \mathrm{C}$ exhibited a small contraction when loaded to $25 \%$ of the ultimate load; the initial deforma-

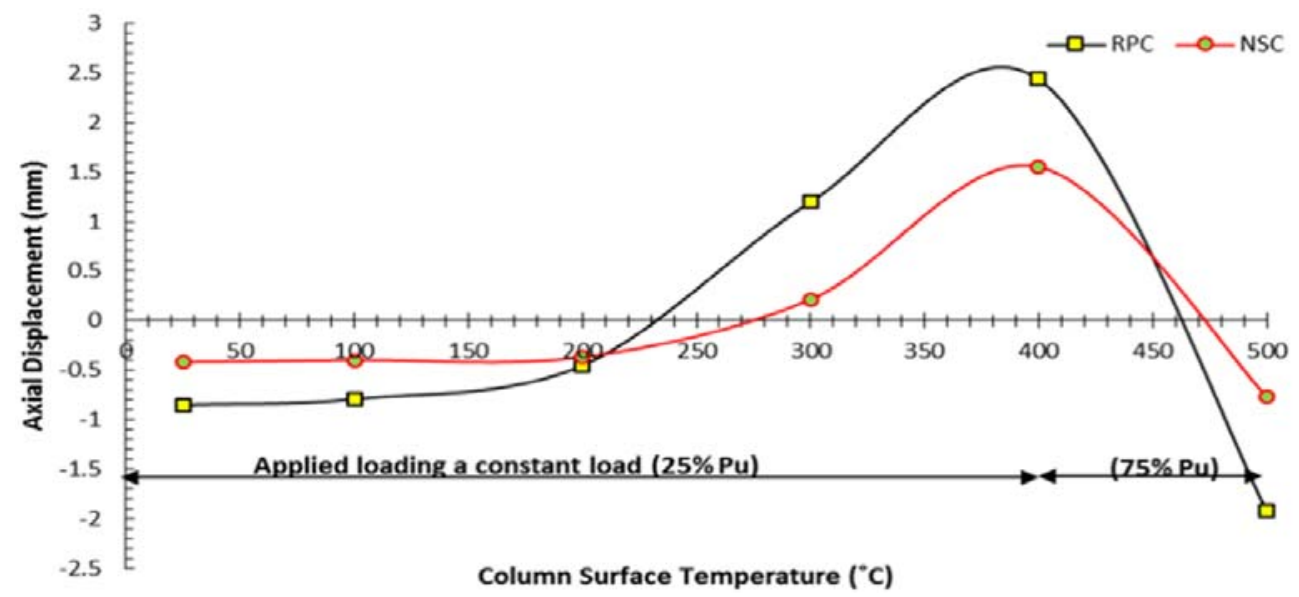

FIGURE 4. Comparison of vertical displacements of RPC and NSC columns after exposure to fire 


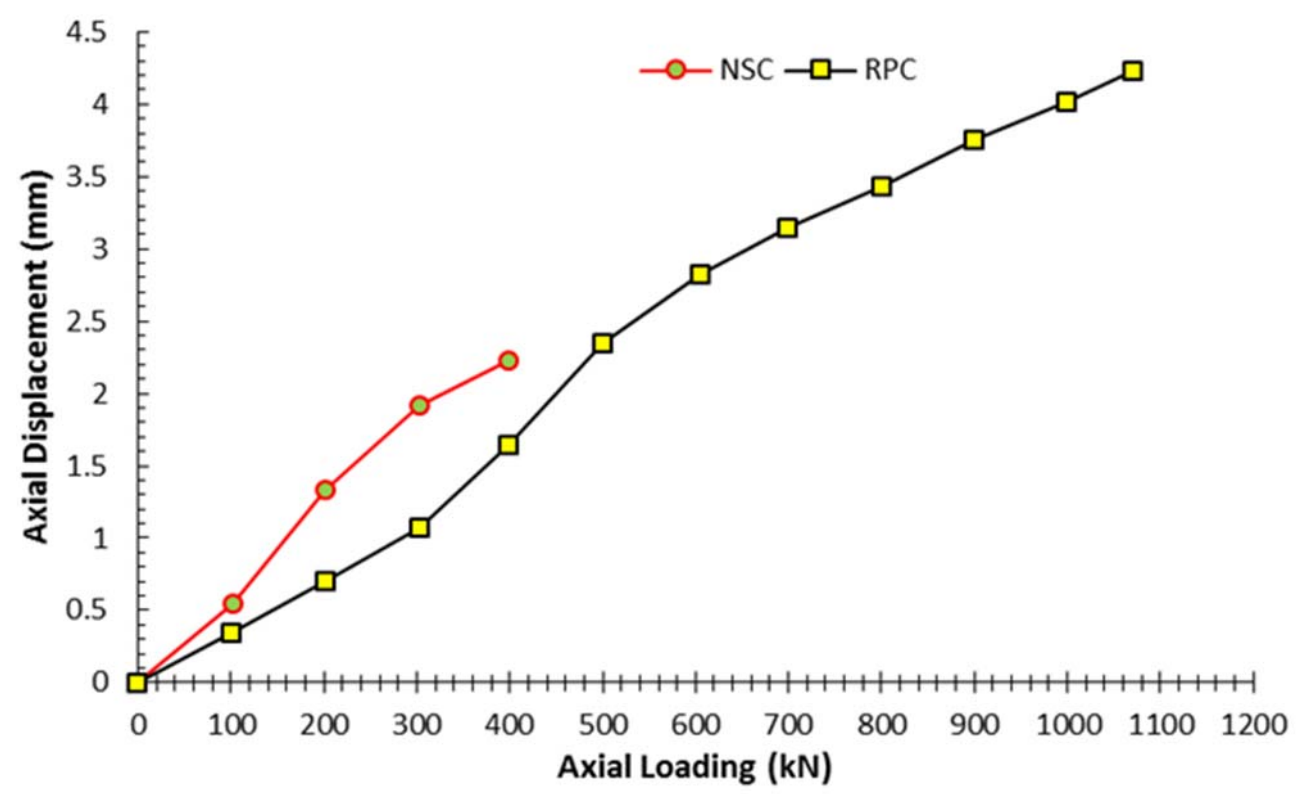

FIGURE 5. Comparison of vertical displacements of the reference RPC and NSC columns

tion (expansion) of the RPC and NSC column specimens was mostly because of the thermal concrete expansion and steel, though in the intermediate stages both load and thermal expansion had a substantial influence. In the succeeding stages, the creep influence becomes clear due to the high temperature. The contraction of the RPC and NSC columns after the exposure duration is finished could be attributed to the loss in stiffness and strength of the steel and concrete. Finally, Figure 3 shows the column surface temperature versus the vertical deformation in the y-direction (elongation or contraction) for RPC and NSC columns at different stages during loading and heating, while Figure 5 shows the vertical displacement for RPC and NSC columns due to loading at the normal temperature of the room $\left(25^{\circ} \mathrm{C}\right)$.

\section{Pattern of cracks and spalling}

By inspecting each case, it is clear that, despite the good agreement in the measured parameters, an obvious aberration in the values of the extent of the cracks may be noticed between the tested columns in each instance. The cracks, which appeared in the columns, can be classified according to the acting loading condition, as: pure axial concentric load; pure thermal stress; combined thermal stress and axial load.

Pure axial concentric load. In this study, one column from each group was tested at room temperature in order to be the reference for the other columns. The columns failed by compression mode (crushing) and the cracks appeared in a conical pattern like the failure of the cylinder in a compression test, as shown in Figure 6. 


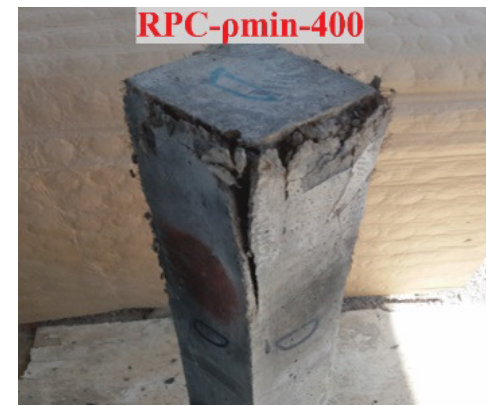

FIGURE 6. Typical crack pattern of pure axial concentric load columns

Pure thermal stress. In this study, the thermal stress that resulted when the columns were exposed to fire differed in intensity. Different cracks appeared in each stage (stages A, B, C, D):

A. During 30-45 min of exposure to fire at $300^{\circ} \mathrm{C}$, hairline cracks appeared at the middle portion of the column specimens.

B. During 21-36 min of exposure to fire at $400^{\circ} \mathrm{C}$, hairline cracks and surface spalling appeared in the RPC column; before that, the sound of crack propagation was heard. The surface spalling occurs due to the pore pressure (Klingsch, 2014).

C. Sloughing-off spalling (non-violent breaking off of concrete fragments) and corner spalling (removal of the concrete cover from the corner) occurred during 40-55 min of exposure to fire at $400^{\circ} \mathrm{C}$. Sloughing-off spalling occurs due to longer exposure, corner spalling occurs due to the temperature impact from two sides (Klingsch, 2014).

D. Explosive spalling took place in RPC columns at $500^{\circ} \mathrm{C}$. An assumption is proposed that the combined thermal stresses and pore pressure caused this explosive spalling (Khoury \& Anderberg, 2000). The pore pressure ensuing from explosive spalling may, in short, be defined as follows: moisture is created within the pore concrete system along with temperature increases. This moisture increases when the temperature is above $100^{\circ} \mathrm{C}$, water as liquid and vapor are present inside the pore system. The presence of pressure occurs due to the pore saturation degree and the building temperature. A part of this vapor is liberated through the voids and pores depending on the concrete permeability; nevertheless, pore pressure rises as long as adequate moisture is obtainable.

\section{Combined thermal stress and axi-}

al load. The present research focuses on the structural behavior of the columns exposed to burning under loading, which is a real situation that represents the chemical changing of the microstructure of a building by raising the temperature levels during the burning of the member and as follows:

A. All NSC columns failed by compression mode; diagonal cracks appeared at the middle third of columns at $75-80 \%$ of the failure load, followed by crushing and rupture of certain ties.

B. At $300^{\circ} \mathrm{C}$, the RPC failed by compression mode. A set of cracks appeared on the column faces, approximately $80 \%$ of the failure load; the cracks seen on the columns were vertical and diagonal.

C. At $400^{\circ} \mathrm{C}$, the unreinforced RPC column failed by flexural mode, while the reinforced RPC column failed in compression mode. 


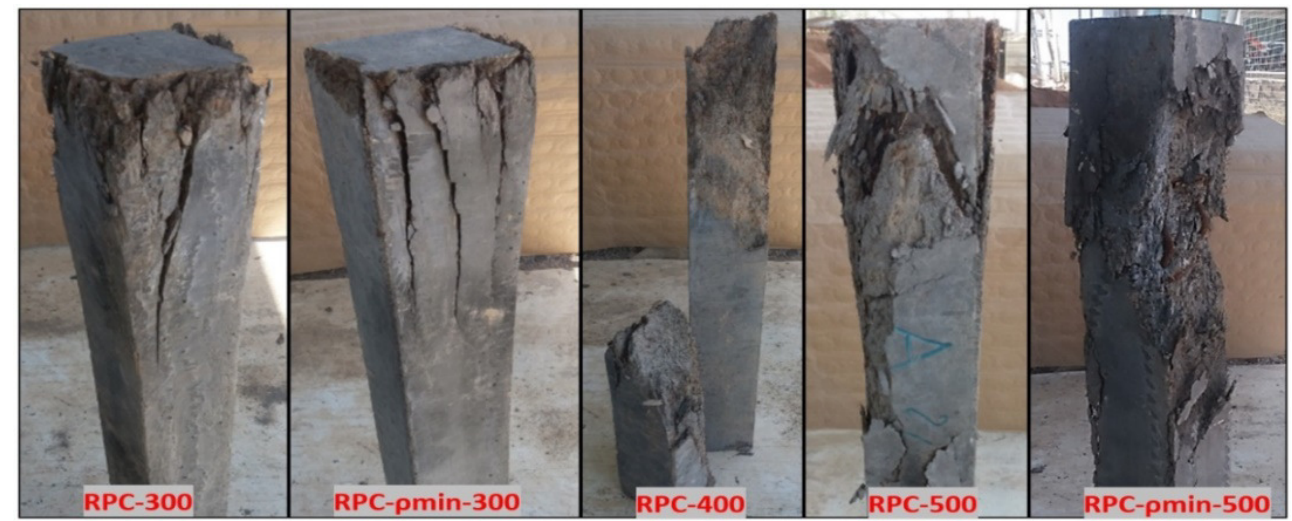

FIGURE 7. Failure mode of RPC columns due to combined thermal stress and axial load at different temperature levels

D. The deterioration of the RPC at $500^{\circ} \mathrm{C}$ appeared in two forms: local damage (cracks) in the material itself, and global damage resulting from flexural failure at the first third of the column.

The mode of failure of the RPC columns due to combined thermal stress and axial load is shown in Figure 7.

Finally, the authors recommend, basing on the successful use of electromagnetic sensors in many fields (Gkantou, Muradov, Kamaris, Atherton \& Kot, 2019; Ryecroft et al., 2019a; Ryecroft et al., 2019b; Teng et al., 2019), using of embedded sensors in the concrete members to monitor the progress of temperature that helps to have a better understanding for the effects of fire on concrete structures.

\section{Conclusions}

This research has studied the post-fire performance of reactive powder concrete columns exposed to fire at different temperature levels $(300,400$ and $500^{\circ} \mathrm{C}$ ) and for two durations (30 and
$60 \mathrm{~min})$. From the outcome of our investigation, it is possible to conclude that:

- The residual strength of RPC columns drops with increasing temperature starting at $300^{\circ} \mathrm{C}$.

- Based on the experimental results, explosive spalling occurred in a period of up to $30 \mathrm{~min}$ of heating. At all times, minor spalling took place first, followed by major and severe spalling.

- The deterioration of the RPC at $500^{\circ} \mathrm{C}$ appeared in two forms: local damage (cracks) in the material itself and global damage resulting from failure in the column.

- Compared to the fire resistance of NSC, RPC has a higher susceptibility to fire-induced spalling. This is possibly due to the low permeability and the high density of RPC, which prevents water vapor from escaping at elevated temperatures and leads to high pore pressure, which produces spalling.

- Explosive spalling took place in $\mathrm{RPC}$ columns at $500^{\circ} \mathrm{C}$ due to pore pressure. 
- The residual strength of reinforced RPC columns is greater than that of the unreinforced columns at high temperatures because the longitudinal reinforcement confined the core of the column and prevent it from spalling.

\section{References}

Abdulraheem, M.S. (2018). Experimental investigation of fire effects on ductility and stiffness of reinforced reactive powder concrete columns under axial compression. Journal of Building Engineering, 20, 750-761.

Abdulraheem, M.S. \& Kadhum, M.M. (2018). Experimental and numerical study on post-fire behaviour of concentrically loaded reinforced reactive powder concrete columns. Construction and Building Materials, 168, 877-892.

ASTM International (2005). Standard specification for silica fume used in cementitious mixtures (ASTM C1240-05). West Conshohocken, PA: ASTM International.

Central Organization for Standardization and Quality Control [CCSQC] (1984). Aggregate from natural sources for concrete and construction (IQS 45/1984). Baghdad: Central Organization for Standardization and Quality Control.

Gkantou, M., Muradov, M., Kamaris, G.S., Atherton, W. \& Kot, P. (2019). Novel electromagnetic sensors embedded in reinforced concrete beams for crack detection. Sensors, 19(23), 5175-5189.

Hager, I., Zdeb, T. \& Krzemien, K. (2013). The impact of the amount of polypropylene fibres on spalling behaviour and residual mechanical properties of Reactive Powder Concretes. MATEC Web of Conferences, 6(1), 02003-02016.

Kadhum, M. (2015). Prediction of Mechanical Properties of Reactive Powder Concrete by Using Artificial Neural Network and Regression Technique after the Exposure to Fire Flame. Jordan Journal of Civil Engineering, 9(3), 1-15.
Kadhum, M.M., Alwash, N.A., Tuama, W.K. \& Abdulraheem, M.S. (2020). Experimental and numerical study of influence of crude oil products on the behavior of reactive powder and normal strength concrete slabs. Journal of King Saud University - Engineering Sciences, 32(5), 293-302.

Kadhum, M.M. \& Mohammed, Z.A. (2017). Predict the Ultimate Moment Capacity of Reactive Powder Concrete Beams Exposed to Fire Flame Using Artificial Neural Network and Multiple Linear Regression Models. International Journal of Engineering and Technology (IJET), 9(3), 2637-2649.

Khoury, A. \& Anderberg, Y. (2000). Fire Safety Design - Concrete Spalling Review. Swedish Borlänge: National Road Administration.

Klingsch, E.W. (2014). Explosive spalling of concrete in fire. IBK Bericht, 356(1), 1-13.

Kodur, V. \& Raut, N. (2012). A simplified approach for predicting fire resistance of reinforced concrete columns under biaxial bending. Engineering Structures, 41, 428-443.

Liu, C-T. \& Huang, J-S. (2009). Fire performance of highly flowable reactive powder concrete. Construction and Building Materials, 23(5), 2072-2079.

Ryecroft, S., Shaw, A., Fergus, P., Kot, P., Hashim, K., Moody, A. \& Conway, L. (2019a). A First Implementation of Underwater Communications in Raw Water Using the $433 \mathrm{MHz}$ Frequency Combined with a Bowtie Antenna. Sensors, 19(8), 1813-1823.

Ryecroft, S., Shaw, A., Fergus, P., Kot, P., Hashim, K. \& Conway, L. (2019b). A Novel Gesomin Detection Method Based on Microwave Spectroscopy. In D. Al-Jumeily et al. (eds.), $12^{\text {th }}$ International Conference on Developments in eSystems Engineering (DeSE 2019) (pp. 429-433). IEEE Computer Society Conference Publishing Services. https://doi.org/10.1109/DeSE.2019.00085

Tai, Y-S., Pan, H-H. \& Kung, Y-N. (2011). Mechanical properties of steel fiber reinforced reactive powder concrete following exposure to high temperature reaching $800^{\circ} \mathrm{C}$. Nuclear Engineering and Design, 241(7), 2416-2424.

Teng, K.H., Kot, P., Muradov, M., Shaw, A., Hashim, K., Gkantou, M. \& Al-Shamma'a, A. (2019). Embedded Smart Antenna for 
Non-Destructive Testing and Evaluation (NDT\&E) of Moisture Content and Deterioration in Concrete. Sensors, 19(3), 547-559.

Tuama, W., Kadhum, M., Alwash, N., Al-Khafaji, Z. \& Abdulraheem, M. (2020). RPC Effect of Crude Oil Products on the Mechanical Characteristics of Reactive-Powder and Normal-Strength Concrete. Periodica Polytechnica Civil Engineering, 64(2), 422-429.

Yan, G. (2009). Application of reactive powder concrete in highway barriers. In Q. Peng et al. (eds.), International Conference on Transportation Engineering 2009 (pp. 7-12). American Society of Civil Engineers. https:// doi.org/10.1061/9780784410394

\section{Summary}

Experimental investigation on the post-fire performance of reactive powder concrete columns. The increased use of reactive powder concrete (RPC) in concrete structures has attracted attention towards the structural behavior of RPC in fires. This work examines experimentally the performance of RPC and NSC columns subjected to $25 \%$ of the ultimate load and exposed to direct fire flame for a period of 30 and $60 \mathrm{~min}$ at various temperature levels. The paper aims to evaluate the maximum temperature level and fire duration that can be withstood by this type of concrete columns. The results show that the failure mode of RPC columns without reinforcement is a sudden shear failure, whereas the failure mode of reinforced RPC columns is a crushing failure with rupture of certain ties. The RPC columns at high temperatures spall intensively; additionally, the ultimate strength clearly decreases compared to the NSC columns at the same conditions.

\section{Authors' address:}

Mohammed M. Kadhum

(https://orcid.org/0000-0002-4732-3646)

University of Babylon

College of Engineering

Department of Civil Engineering

Al Hilla, 51001

Iraq

e-mail: eng.mohammed.mansour@uobabylon. edu.iq

Zainab H. Mahdi

Middle Technical University

Technical Engineering College

Baghdad, 10001

Iraq

e-mail: zaideng.2004@yahoo.com

Yousif Taha Funfakh

University of Babylon

College of Engineering

Department of Civil Engineering

Al Hilla, 51001

Iraq

e-mail: eng.mohammed.mansour@uobabylon. edu.iq

Zaid Mohammed

University of Technology

Building and Construction Engineering

Department

Baghdad, 10001

Iraq

e-mail: zainabengineeringcollege@yahoo.com

Mustafa Abdulraheem - corresponding author General Company of electricity distribution for the middle region, Karbala branch

Karbala, 5600

Iraq

e-mail: mostfa_seham@yahoo.com

Michaela Gkantou

Liverpool John Moores University

School of Civil Engineering and Built

Environment

Liverpool, L3 3AF

UK

e-mail: M.Gkantou@ljmu.ac.uk 